\title{
Manejo das pastagens de inverno e potencial produtivo de sistemas de integração lavoura-pecuária no Estado do Rio Grande do Sul
}

\author{
Winter pastures management and productive potential of mixed systems in Rio Grande do Sul State, Brasil
}

\author{
Rodrigo da Silveira Nicoloso ${ }^{1}$ Mastrângello Enívar Lanzanova ${ }^{2}$ Thomé Lovato $^{2}$
}

\section{RESUMO}

Para avaliar o impacto de diferentes freqüencias de pastoreio bovino em pastagens anuais de inverno sobre o rendimento zootécnico e na produtividade de grãos das culturas de verão em sistemas mistos (integração lavoura-pecuária), conduziu-se um experimento a campo no município de Jari$R S$. Foram avaliados três tratamentos referentes ao manejo das pastagens de inverno, a saber: sem pastoreios (SP), pastoreios a cada 28 dias (P28) e pastoreios a cada 14 dias (P14); e dois referentes às culturas de verão, sendo elas: soja $e$ milho. A produção animal não foi afetada significativamente pela freqüência de pastoreio adotada, porém notou-se redução na produção de palhada para cobertura de solo à medida que se intensificou a utilização das pastagens. Da mesma maneira. o rendimento de grãos da soja e do milho em sucessão nestas áreas foi reduzido pelo aumento da freqüência de pastoreio. Nas áreas que não receberam pastoreios durante o inverno $(\mathrm{SP})$, o rendimento de grãos de soja e milho foi de 3,2 e 7,8Mg $\mathrm{ha}^{-1}$, respectivamente. $O$ tratamento $P 28$ não diferiu significativamente do tratamento $S P$ quanto ao rendimento de grãos de soja e milho, enquanto que, no tratamento P14, houve a redução no rendimento destas culturas da ordem de 0,78 e $1,29 \mathrm{Mg} \mathrm{ha}^{-1}$, respectivamente.

Palavras-chave: rotação de culturas, rendimento de grãos, ganho de peso animal, sistema plantio direto.

\section{ABSTRACT}

To evaluate different grazing frequencies over winter pastures impact on the beef cattle yield and crop yield of summer species in beef cattle and crop systems, a field experiment was carried out in Jari, RS. Three management treatments were evaluated: no grazing $(N G)$, grazing every 28 days (G28) and grazing every 14 days (G14); and two summer species treatments: soybean and corn. Beef cattle yield wasn't affected significantly by the grazing frequencies, but it could be observed reduction on mulch production with the increase of the winter pastures use intensity. Soybean and corn grain yield succeeded on these areas were reduced by the increase of the grazing frequencies. In the areas which did not receive grazing on the winter $(N G)$ the soybean and corn grain yield was 3.2 and $7.8 \mathrm{Mg} \mathrm{ha} \mathrm{a}^{-1}$, respectively. The $\mathrm{G} 28$ treatment wasn't significantly different to the NG treatment about the soybean and corn grain yield, however 614 treatment, had reduction of these cultures grain yield of 0.78 and $1.29 \mathrm{Mg} \mathrm{ha}^{-1}$, respectively.

Key words: crop rotation, grain yield, weight gain, no tillage.

\section{INTRODUÇÃO}

Segundo MORAES et al. (1998), define-se integração lavoura-pecuária (ILP) como a alternância temporária ou a rotação, numa mesma área, de culturas de grãos e pastagens destinadas ao pastoreio animal. Apesar de poucos trabalhos terem sido publicados sobre este assunto, a ILP não é propriamente uma atividade nova no Estado do Rio Grande do Sul (RS). Segundo o último Censo Agropecuário realizado no Brasil, cerca de $16 \%$ da superfície agrícola deste Estado, ou aproximadamente 3,4 milhões de hectares, envolviam sistemas mistos de exploração agropecuária (IBGE, 1996). Não obstante isso, a forte expansão das áreas de lavouras produtoras de grãos sobre regiões anteriormente ocupadas com a pecuária de corte extensiva e o concomitante crescimento do rebanho bovino gaúcho, ocorridos nos últimos anos, reiteram a importância da ILP como atividade econômica e objeto de pesquisa. No RS, como em toda a Região Sul do país, a ILP caracteriza-se basicamente pela utilização de pastagens anuais de inverno para pastoreio bovino e a ocupação destas mesmas áreas com as culturas da

${ }^{1}$ Departamento de Solos, Centro de Ciências Rurais (CCR), Universidade Federal de Santa Maria (UFSM), 97105-900, Santa Maria, RS, Brasil. E-mail: rsnicoloso@mail.ufsm.br. Autor para correspondência.

2Departamento de Solos, CCR, UFSM, Santa Maria, RS, Brasil. E-mail: mlanzanova@mail.ufsm.br. 
soja e do milho durante o verão. Sendo assim, o correto manejo das pastagens de inverno é decisivo não somente para a obtenção de bons rendimentos zootécnicos, mas também para definir o potencial produtivo das culturas de verão, especialmente no Sistema Plantio Direto (SPD).

O SPD, como um sistema conservacionista de manejo de solo, exige para o seu sucesso, que o solo se mantenha coberto durante todo o ano e, para tanto, um aporte abundante e constante de resíduos vegetais (MIELNICZUK, 1988). Sendo assim, a utilização das pastagens de inverno para pastoreio bovino pode limitar consideravelmente a quantidade de palha destinada à cobertura de solo, comprometendo então a sustentabilidade da atividade agropecuária. Alguns trabalhos de pesquisa demonstram que, para as condições climáticas do RS, a adição anual de palha ao solo no SPD não deve ser menor que 8,65 (NICOLOSO, 2005) ou 8,07 (LOVATO et al., 2004) Mg ha $^{-1}$ de matéria seca dos resíduos vegetais da parte aérea vegetal para que se mantenham estáveis os teores de matéria orgânica do solo (MOS). Além da manutenção dos estoques de MOS, sistemas de culturas que promovam alta adição de resíduos vegetais sobre o solo, proporcionam maior comprimento do sistema radicular das culturas, permitindo assim uma melhor exploração do perfil do solo (SÁ et al., 2004), uma maior taxa de infiltração de água no solo (LANZANOVA, 2005), uma menor susceptibilidade do solo à compactação (BRAIDA el al., 2004) e uma maior ciclagem de nutrientes (GIACOMINI et al., 2003), fatores estes que concorrem para a obtenção de altas produtividades animal e vegetal.

O sistema de pastoreio rotativo ou "Voisin" (VOISIN, 1974) é um método de manejo de pastagens bastante difundido no mundo inteiro e caracteriza-se pela divisão da área de pastagem em parcelas menores ou "piquetes", nos quais os animais entram quando o mesmo apresenta uma quantidade de forragem suficiente para que seja realizado o pastoreio e saem quando o nível de forragem atinge um limite inferior pré-estabelecido, passando, após isso, para o próximo piquete ainda não pastejado. Desta maneira, os animais passam de piquete em piquete, até retornarem ao primeiro, quando este apresentar novamente condições de ser pastejado. Este sistema de pastoreio permite um melhor aproveitamento da pastagem por evitar a seletividade da forragem pelo animal (ROVIRA, 1996) e por permitir um período de descanso para que as plantas pastejadas possam recuperar-se e atingir novamente altas taxas de crescimento (VOISIN, 1974).
Um sistema de pastoreio rotativo, caracteriza-se, portanto, por altas taxas de lotação em cada piquete por um curto período de tempo. Desta maneira, o intenso pisoteio bovino ocorrido nestas áreas pode gerar problemas de compactação do solo. TREIN et al. (1991) observaram que, após a aplicação de uma alta taxa de lotação animal em curto período de tempo, houve aumento da resistência do solo à penetração, diminuição da macroporosidade e redução significativa da infiltração de água no solo na camada $0-0,075 \mathrm{~m}$ de um Argissolo Vermelho, cultivado com pastagens de inverno. Também BERTOL et al. (1998) observaram resultados semelhantes ao avaliarem diferentes taxas de ofertas de forragem de uma pastagem natural da depressão central do RS. Neste trabalho, os autores notaram aumento da densidade do solo na camada de 0,03 a $0,06 \mathrm{~m}$ de profundidade, quando foram aplicadas maiores pressões de pastoreio (4 e $8 \%$ em relação a 10 e $12 \%$ de oferta de forragem para cada $100 \mathrm{~kg}$ de peso vivo animal por hectare). No entanto, CLARK et al. (2004), que avaliaram os efeitos do pastoreio rotativo (28 dias de intervalo) de uma resteva de lavoura de milho nas propriedades físicas do solo e na produtividade de grãos de soja subseqüente, em sistema plantio direto, durante três anos, observaram que a população de plantas de soja e o rendimento de grãos não foram afetados pelo pisoteio bovino, bem como a densidade do solo, que manteve valores muito próximos dos encontrados nas áreas não pastejadas. LANZANOVA (2005) observou que o aumento da freqüência de pastoreio sobre as pastagens de inverno provoca o aumento da densidade do solo na camada 0 - 0,05m, aumento da resistência do solo à penetração e diminuição da taxa de infiltração de água no solo, afetando negativamente o rendimento de grãos da soja ou do milho subseqüentes. No entanto, o autor observou que este processo é reversível e, durante o ciclo de crescimento das culturas de verão, o solo retorna a sua condição anterior.

A divergência entre os resultados de pesquisa existentes na literatura torna necessário um estudo mais aprofundado sobre os impactos que o manejo aplicado sobre as pastagens de inverno provocam sobre a produtividade animal destas pastagens e o rendimento de grãos das culturas de verão, a fim de definir-se o potencial produtivo de áreas de ILP e a sua viabilidade econômica e agronômica.

\section{MATERIAL E MÉTODOS}

O estudo constou da instalação de um experimento de campo em área pertencente à Agropecuária Capitão Rodrigo, situada no município 
de Jari, RS (longitude $54^{\circ} 13^{\prime} \mathrm{W}$, latitude $29^{\circ} 17^{\prime} \mathrm{S}$ e altitude $441 \mathrm{~m}$ ), na região do Planalto Médio gaúcho. O clima da região é do tipo Cfa 1 , segundo a classificação de Köppen, com precipitações e temperaturas médias anuais variando de 1558 a $1762 \mathrm{~mm}$ e de 17,1 a $17,9^{\circ} \mathrm{C}$, respectivamente (BRASIL, 1973). O solo do local é descrito como sendo um Argissolo Vermelho-Amarelo alumínico típico (EMBRAPA, 1999).

Até o ano de 2001, antes da instalação do experimento, a área experimental era mantida sob pastagem natural com a exploração de bovinocultura de corte sob pastoreio extensivo. Em outubro de 2001, por ocasião da implantação do experimento, a camada de solo de $0-0,10 \mathrm{~m}$ foi amostrada e os resultados da análise da fertilidade do solo foram: $280 \mathrm{~g} \mathrm{~kg}^{-1} \mathrm{de}$ Argila, pH: 4,9, P: 2,7ppm, K: 155ppm, M.O.: $45 \mathrm{~g} \mathrm{~kg}^{-1}$, Al: 9,7mmolc dm ${ }^{-3}$, Ca: $30 \mathrm{mmolc} \mathrm{dm}^{-3}, \mathrm{Mg}: 1,3 \mathrm{mmol}_{\mathrm{c}} \mathrm{dm}^{-3}$, $\mathrm{H}+\mathrm{Al}: 69,7 \mathrm{mmol}_{\mathrm{c}} \mathrm{dm}^{-3}$, CTC efetiva: $56 \mathrm{mmol}_{\mathrm{c}} \mathrm{dm}^{-3}$, CTC pH 7: $116,4 \mathrm{mmol}_{\mathrm{c}} \mathrm{dm}^{-3}$, Saturação por Al: $170 \mathrm{~g} \mathrm{~kg}^{-1} \mathrm{e}$ Saturação por Bases: $403,3 \mathrm{~g} \mathrm{~kg}^{-1}$. Foram aplicadas em superfície $3 \mathrm{Mg} \mathrm{ha}^{-1}$ de calcário dolomítico (PRNT $100 \%$ ) e, em novembro de 2001 , procedeu-se à dessecação da pastagem nativa e à implantação das culturas da soja e do milho, em sistema plantio direto. Os resultados apresentados neste trabalho referem-se aos dados obtidos no experimento durante o último ano de avaliação, entre abril de 2004 e março de 2005.

O delineamento experimental utilizado foi o bifatorial $3 \times 2$, disposto em blocos ao acaso, com quatro repetições. Aárea de cada parcela foi de $60 \mathrm{~m}^{2}$. O fator $A$ foi constituído por três sistemas de manejo das pastagens de inverno: sem pastoreio (SP), pastoreio a cada 28 dias (P28) e pastoreio a cada 14 dias (P14) e o fator B constou de duas culturas de verão: soja (Glycine max (L.) Merr.) e milho (Zea mays L.). As pastagens de inverno foram semeadas durante o mês de abril de cada ano de condução do experimento e eram formadas por um consórcio de aveia preta (Avena strigosa Schreb.) e azevém (Lolium multiflorum Lam.), na proporção de $80 \mathrm{~kg} \mathrm{ha}^{-1}$ de sementes viáveis de aveia preta e de $20 \mathrm{~kg} \mathrm{ha}^{-1}$ de sementes viáveis de azevém. O azevém foi semeado a lanço e incorporado ao solo com a passagem de uma semeadeira para plantio direto que continha as sementes de aveia preta, semeadas em linha, com espaçamento de $0,175 \mathrm{~m}$. Os pastoreios foram realizados aos 60, 88 e 116 dias após a emergência das pastagens para o sistema P28 e aos 60, 74, 88, 102 e 116 dias após a emergência das forrageiras para o sistema P14. Foram utilizadas fêmeas de bovinos da raça Aberdeen Angus, com peso aproximado de $350 \mathrm{~kg}$ cada. Esses bovinos permaneciam na pastagem por aproximadamente duas horas, sendo retirados da área quando o resíduo da pastagem atingia uma altura mínima aproximada de $0,10 \mathrm{~m}$. Após isso, para o sistema P28, utilizava-se um período de descanso de 28 dias, até os animais retornarem à pastagem, e para o sistema P14, o período de descanso era de 14 dias. Após o último pastoreio, as pastagens eram deixadas em descanso por um período de um mês para que acumulassem fitomassa para cobertura de solo, para a posterior dessecação e realização da semeadura das culturas de verão. As pastagens de inverno não receberam adubação nitrogenada. A adubação fosfatada e potássica foi realizada somente para as culturas da soja e do milho, conforme as recomendações da CFS RS/SC (1995) para estas culturas. O milho e a soja foram semeados no mês de novembro de cada ano de condução do experimento, sendo que o milho foi semeado em linha, com espaçamento de $0,70 \mathrm{~m}$ e população desejada de 55.000 plantas ha-1 ${ }^{-1}$ e a soja foi semeada em linha com espaçamento de $0,35 \mathrm{~m}$ e população desejada de 300.000 plantas ha-1 . O milho recebeu $120 \mathrm{~kg} \mathrm{ha}^{-1}$ de nitrogênio, tendo sido aplicado $30 \mathrm{~kg} \mathrm{ha}^{-1}$ por ocasião da semeadura e o restante parcelado em duas aplicações durante os estádios $\mathrm{V}_{4-6} \mathrm{e}$ V8-10 de desenvolvimento da cultura. A soja foi inoculada com Rhizobium específico para a cultura. Os demais tratos culturais aplicados, referentes à utilização de herbicidas, inseticidas ou fungicidas, seguiram as recomendações técnicas vigentes para o Estado do Rio Grande do Sul.

O ganho de peso animal por hectare obtido ao final do período de utilização da pastagem foi calculado em função da quantidade de matéria seca (MS) consumida pelos animais durante os pastoreios e de uma conversão alimentar média dos bovinos, que segundo RESTLE et al. (1998); FONTANELI et al. (2000), pode ser de $10 \mathrm{~kg}$ de MS consumida para $1 \mathrm{~kg}$ de ganho de peso vivo. A lotação animal foi calculada em função da quantidade de forragem consumida pelos animais e com base nos dados de ROVIRA (1996), que indica o consumo de $3 \%$ do peso vivo por dia de MS vegetal por vaca de $350 \mathrm{~kg}$, quando as plantas estão no estádio vegetativo.

A quantidade de forragem consumida pelos animais durante o pastoreio foi determinada através da coleta de amostras da forragem disponível em cada parcela antes e após a realização dos pastoreios. Da mesma maneira, para a determinação da adição de palha ao solo em cada sistema de culturas, foram coletadas amostras da parte aérea vegetal para a mensuração da matéria seca adicionada ao solo pelas pastagens de inverno (ao final do período reservado para o seu diferimento) e pelas culturas da soja e milho. As amostras das pastagens de inverno foram coletadas com o auxílio de um anel de aço com $0,1 \mathrm{~m}^{2}$ de área 
interna. A cultura da soja foi amostrada quando as plantas estavam no estádio $\mathrm{R}_{4}$, no qual, segundo PADOVAN et al. (2002), determina-se a quantidade de material vegetal aportado ao solo por esta cultura ao final do seu ciclo. Para tanto, foram coletadas as plantas de soja presentes em dois metros lineares da área útil da parcela. A cultura do milho foi amostrada por ocasião da sua maturação fisiológica. Foram coletadas aleatoriamente quatro plantas de milho por parcela. Todas as avaliações foram constituídas por quatro repetições. $\mathrm{O}$ material coletado foi levado à estufa de ventilação forçada e secado a $60 \pm 5^{\circ} \mathrm{C}$, até que atingisse peso constante.

O rendimento de grãos das culturas de verão foi determinado através da coleta de dois metros lineares de soja por amostra e das espigas de oito plantas de milho colhidas ao acaso no interior da parcela, por amostra. O material colhido foi embalado, debulhado manualmente e os grãos obtidos foram pesados e tiveram sua umidade ajustada a $13 \%$, determinando-se assim o rendimento de grãos. Os resultados obtidos no experimento foram submetidos à análise de variância, ao teste $\mathrm{F}$ em nível de $5 \%$ de probabilidade de erro e a comparação de médias foi feita pelo teste de Tukey em nível de 5\% de probabilidade de erro.

\section{RESULTADOS E DISCUSSÃO}

Em anos favoráveis ao desenvolvimento das pastagens, como foi o inverno de 2004, que apresentou boa disponibilidade de luz e água às plantas durante todo o inverno, a freqüência de pastoreio costuma ter menor impacto sobre a taxa de crescimento das pastagens. Sendo assim, a disponibilidade de forragem semelhante entre os dois sistemas de pastoreio resultou em uma menor taxa de lotação nos primeiros períodos de pastoreio na freqüência de 28 dias, o que certamente provocou a redução do ganho de peso ao final do período de pastoreio neste sistema, embora esta não tenha sido significativa (Tabela 1).

A carga animal utilizada em ambas as freqüências de pastoreios foi semelhante à observada por CASSOL (2003) em áreas de integração lavoura-pecuária sob pastoreio contínuo, quando foram aplicadas maiores pressões de pastoreio, mantendo a altura de manejo das pastagens em cerca de $0,10 \mathrm{~m}$. Ainda assim, cabe salientar que, no tratamento P14, o período total de pastoreio foi 14 dias menor do que no tratamento P28, por terem ocorrido 5 e 3 ciclos de pastoreios, respectivamente. Apesar disso, o ganho de peso no tratamento P14 não foi prejudicado, o que demonstra o seu caráter mais intensivo.

À medida que se avança no ciclo das pastagens de inverno, tem-se aumento no ganho de peso animal em cada período de pastoreio. Isso indica a maior contribuição do azevém na oferta de forragem nestes períodos, devido a suas maiores taxas de crescimento no período de inverno e início da primavera. Estes dados concordam com os de RESTLE et al. (1998), que apontam o período de final do inverno e início da primavera como o período de maiores taxas de crescimento das pastagens de inverno.

$\mathrm{O}$ ganho de peso vivo diário por animal estimado foi de $1,05 \mathrm{~kg} \mathrm{PV} \mathrm{ha}^{-1}$, e sendo calculado em função da lotação animal e do ganho de peso no período de pastoreio, ficando próximos aos observados

Tabela 1 - Lotação animal, período de pastoreio e ganho de peso animal em função da frequiência de pastoreio empregada sobre as pastagens de inverno em um Argissolo Vermelho-Amarelo Alumínico.

\begin{tabular}{cccccc}
\hline \multirow{3}{*}{ Tratamento } & \multicolumn{5}{c}{ Ciclo de pastoreio } \\
\cline { 2 - 6 } & $1^{\mathrm{o}}$ & $2^{\mathrm{o}}$ & $3^{\mathrm{o}}$ & $4^{\mathrm{o}}$ & $5^{\circ}$ \\
\hline
\end{tabular}

Lotação animal

\begin{tabular}{|c|c|c|c|c|c|c|}
\hline P28 & 2,12 & 4,32 & 4,06 & - & - & 3,50 \\
\hline P14 & 4,03 & 3,96 & 5,04 & 5,68 & 4,73 & 4,69 \\
\hline P28 & 530 & 1512 & 1421 & - & - & 1154 \\
\hline P14 & 1410 & 1386 & 1763 & 1988 & 1655 & 1640 \\
\hline & \multicolumn{6}{|c|}{ Duração } \\
\hline
\end{tabular}

\begin{tabular}{|c|c|c|c|c|c|c|}
\hline P28 & 28 & 28 & 28 & - & - & $84^{*}$ \\
\hline \multirow[t]{2}{*}{ P14 } & 14 & 14 & 14 & 14 & 14 & 70 \\
\hline & \multicolumn{6}{|c|}{ Ganho de peso } \\
\hline P28 & 62,26 & 127,09 & 119,40 & - & - & $308,75^{\mathrm{ns}}$ \\
\hline P14 & 59,25 & 58,25 & 74,13 & 83,54 & 69,59 & 344,77 \\
\hline
\end{tabular}

*Soma.

${ }^{\mathrm{ns}}$ Diferença não significativa pelo teste $\mathrm{F}$ em nível de $5 \%$ de probabilidade de erro.

Ciência Rural, v.36, n.6, nov-dez, 2006. 
por RESTLE et al. (1998). Os ganhos de peso animal por área foram semelhantes aos observados por FONTANELI et al. (2000) em áreas de integração lavoura-pecuária sob pastoreio rotativo e intermediários aos obtidos por CASSOL (2003) em áreas de integração lavoura-pecuária sob pastoreio contínuo.

Apesar do efeito deletério do pastoreio bovino não ter reduzido o ganho de peso quando se aumentou a frequiência de pastoreios, quando a preocupação torna-se acumular fitomassa vegetal para cobertura de solo ao final do ciclo de utilização das pastagens de inverno, observou-se mais claramente o efeito restritivo do aumento da freqüência de pastoreio (P14) sob a taxa de crescimento das pastagens. No período de diferimento das pastagens de inverno, as taxas de crescimento foram de 79,58 e 55,22kg MS ha- ${ }^{-1}$ dia $^{-1}$, para os tratamentos P28 e P14, respectivamente.

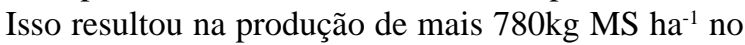
tratamento $\mathrm{P} 28$, que alcançou $3,42 \mathrm{Mg} \mathrm{ha}^{-1}$, em relação ao tratamento P14, que alcançou 2,64Mg ha ${ }^{-1}$ de MS, na média das áreas de pastagem cultivadas em sucessão à soja e ao milho (Tabela 2). Se as pastagens de inverno tivessem sido utilizadas apenas como plantas de cobertura de solo, ter-se-ía a produção de mais de $10 \mathrm{Mg}$ $\mathrm{ha}^{-1}$ de palha (SP), somente no período de inverno. Nesse caso, no entanto, não se produziria mais de $300 \mathrm{~kg}$ $\mathrm{ha}^{-1}$ de carne bovina. Estes dados vão de encontro aos publicados por CASSOL (2003), que observou redução de mais de $4 \mathrm{Mg} \mathrm{ha}^{-1}$ de resíduo final das pastagens de aveia preta e azevém quando utilizou-se uma menor altura de manejo das pastagens, de $0,10 \mathrm{~m}$, sob pastoreio contínuo, em relação a uma área que não foi pastejada.

Considerando que, para o sucesso do SPD, a adição anual de palha para a cobertura de solo não deve ser menor que $8 \mathrm{Mg} \mathrm{ha}^{-1}$ de MS (LOVATO et al.,

Tabela 2 - Adição de matéria seca pela parte aérea das pastagens de inverno e culturas da soja e milho para cobertura de solo no último ano de condução do experimento em um Argissolo Vermelho-Amarelo alumínico.

\begin{tabular}{llllll}
\hline \multicolumn{2}{c}{ Tratamento } & Pastagem & Soja & Milho & Total \\
\hline \multirow{6}{*}{ SP } & Soja & 10,90 & 4,52 & - & 15,42 \\
& Milho & 10,37 & - & 12,75 & 23,12 \\
& & & & & \\
P28 & Soja & 4,05 & 4,03 & - & 8,08 \\
& Milho & 2,80 & - & 11,50 & 14,30 \\
& & & & & \\
P14 & Soja & 2,98 & 3,76 & - & 6,74 \\
& Milho & 2,31 & - & 9,50 & 11,81 \\
\hline
\end{tabular}

2004; NICOLOSO, 2005), dependendo do manejo aplicado sobre as pastagens de inverno e da cultura de verão utilizada, pode-se alcançar este objetivo mesmo em áreas de ILP. Com a utilização da cultura do milho durante o verão, facilmente atinge-se e até supera-se esta necessidade de aporte de palhada ao solo, já que esta cultura produz grande quantidade de fitomassa. No entanto, o monocultivo de soja exige um melhor manejo das pastagens de inverno para que se satisfaça esta exigência, visto que a soja é uma planta com produção de matéria seca relativamente baixa. Além disso, o aumento da intensidade de utilização das pastagens de inverno traz reflexos também sobre a produção de fitomassa das culturas de verão, ao diminuir a sua produção de matéria seca na parte aérea vegetal. Apesar disso, uma alternativa para a utilização da soja em áreas com utilização mais intensiva das pastagens de inverno seria a rotação de culturas de verão com o milho, por exemplo.

O impacto do aumento da freqüência de pastoreios sobre as pastagens de inverno não limita seus efeitos apenas na redução da produção final de palha para cobertura de solo pelas pastagens. $\mathrm{O}$ rendimento de grãos de soja e de milho foram afetados significativamente pelo aumento da freqüência de pastoreio sob as pastagens de inverno antecessoras (Figura 1). Observa-se que o comportamento de ambas as culturas quanto à intensidade de utilização das pastagens de inverno foi semelhante, sendo que, em ambos os casos, o tratamento $\mathrm{P} 14$ reduziu significativamente o rendimento de grãos de soja e de milho em relação ao tratamento que não recebeu pastoreio no inverno (SP), em mais de $780 \mathrm{~kg} \mathrm{ha}^{-1}$ de soja e $1.29 \mathrm{~kg} \mathrm{ha}^{-1}$ de milho. O tratamento P28 apresentou rendimentos intermediários, não diferindo significativamente do tratamento SP, embora tenha apresentando rendimentos inferiores em cerca de $320 \mathrm{~kg}$ ha $^{-1}$ de soja e $620 \mathrm{~kg} \mathrm{ha}^{-1}$ de milho.

Estes dados reforçam os observados por CASSOL (2003), que observou a redução de aproximadamente $1.500 \mathrm{~kg} \mathrm{ha}^{-1}$ do rendimento de grãos de soja quando a altura de manejo das pastagens de inverno passou de $0,40 \mathrm{~m}$ para cerca de $0,10 \mathrm{~m}$. $\mathrm{O}$ autor atribuiu em parte a redução no rendimento da soja à menor população de plantas de soja à medida que se intensificou a carga animal aplicada. No mesmo experimento, mas no ano subseqüente, FLORES (2004) observou resultados semelhantes quando comparou áreas submetidas a diferentes alturas de manejo das pastagens com áreas que não receberam pastoreios no inverno, encontrando redução de aproximadamente $500 \mathrm{~kg} \mathrm{ha}^{-1}$ no rendimento de grãos de soja em áreas manejadas com $0,20 \mathrm{~m}$ de altura de pastagem em relação 


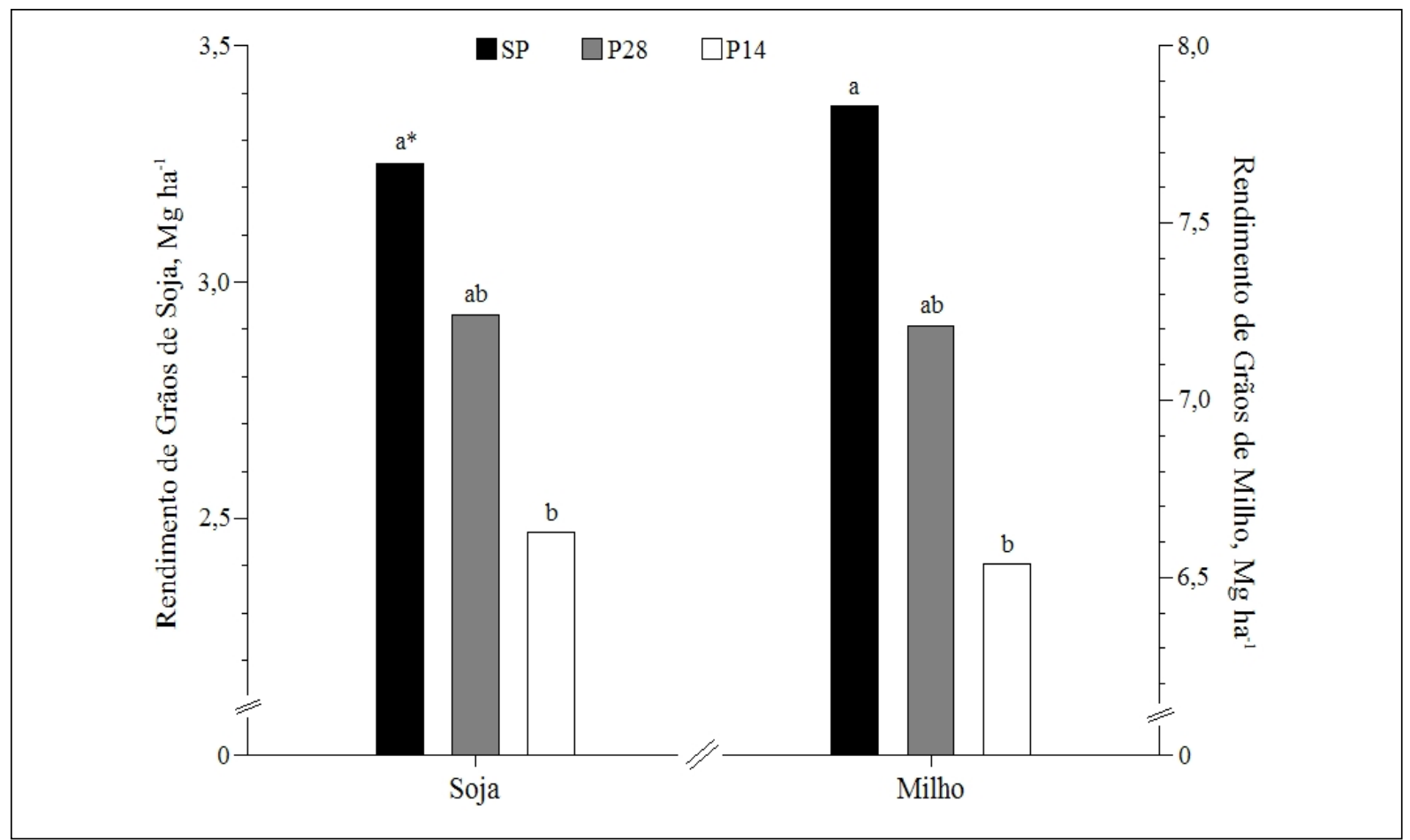

Figura 1 - Rendimento de grãos de soja e de milho em função da freqüência de pastoreio empregada sobre as pastagens de inverno em um Argissolo Vermelho-Amarelo Alumínico. *Médias seguidas pelas mesmas letras não diferem entre si pelo teste de Tukey em nível de $5 \%$ de probabilidade de erro.

a áreas não pastejadas. Neste ano, o autor não observou redução na população de plantas de soja nas áreas pastejadas.

Portanto, como possíveis causas da redução do rendimento das culturas de verão em áreas utilizadas para pastoreio bovino, pode-se apontar a compactação do solo devido ao pisoteio bovino e seus conseqüentes reflexos, como diminuição da macroporosidade, aumento da resistência do solo à penetração de raízes e diminuição da taxa de infiltração de água no solo (LANZANOVA, 2005) e também à depleção dos estoques de MOS (NICOLOSO, 2005).

O processo de compactação do solo é diretamente dependente da umidade do solo durante o período de realização dos pastoreios. Em anos como o de 2004, que apresentou boa distribuição de chuvas durante o inverno, a umidade do solo por ocasião dos pastoreios variou entre 0,23 e $0,27 \mathrm{~m}^{3} \mathrm{~m}^{-3}$. Além disso, observou-se o adensamento da camada $0-0,05 \mathrm{~m}$ de profundidade do solo à medida que se aumentava a frequiência de pastoreios, fato este que não ocorreu nos anos anteriores de realização do experimento, que tiveram inverno com chuvas mal distribuídas e solo mais seco durante a realização dos pastoreios (LANZANOVA, 2005). Da mesma maneira, a redução dos estoques de MOS ocorrida nos tratamentos com maior intensidade de pastoreios ou com menor adição anual de palha ao solo teve alta correlação estatística com a redução do rendimento das culturas de verão nos anos anteriores de avaliação (NICOLOSO, 2005).

\section{CONCLUSÕES}

O sistema de pastoreio rotativo apresenta bom potencial para produção de carne com o uso de pastagens anuais de inverno. $\mathrm{O}$ uso de freqüências elevadas ou alta pressão de pastoreio (P14) sobre as pastagens de inverno limita a produtividade das culturas da soja e do milho em sucessão. A soja em monocultivo de verão exige um manejo das pastagens de inverno menos intensivo (SP ou P28) a fim de que se obtenha boa adição de palha para cobertura de solo.

\section{REFERÊNCIAS}

BERTOL, I. et al. Propriedades físicas do solo relacionadas a diferentes níveis de oferta de forragem numa pastagem natural. Pesquisa Agropecuária Brasileira, Brasília, v.33, n.5, p.779786, 1998.

BRAIDA, J.A. et al. Relações entre a quantidade de palha existente sobre o solo e a densidade máxima obtida no ensaio 
Proctor. In: REUNIÃO BRASILEIRA DE MANEJO E CONSERVAÇÃO DO SOLO E DA ÁGUA, 15., 2004, Santa Maria. Anais... Santa Maria: Sociedade Brasileira de Ciência do Solo, 2004. CD-ROM.

BRASIL. Levantamento de reconhecimento dos solos do estado do Rio Grande do Sul. Brasília: Divisão de Pesquisa Pedológica, Departamento Nacional de Pesquisa Agropecuária (DNPEA), Ministério da Agricultura, 1973. 431p. (Boletim Técnico, 30)

CASSOL, L.C. Relações solo-planta-animal num sistema de integração lavoura-pecuária em semeadura direta com calcário em superfície. 2003. 143f. Tese (Doutorado em Ciência do Solo) - Programa de Pós-graduação em Ciência do Solo, Faculdade de Agronomia, Universidade Federal do Rio Grande do Sul.

CLARK, J.T. et al. Soil surface property and soybean yield response to corn stover grazing. Agronomy Journal, Madison, v.96, p.1364-1371, 2004.

COMISSÃO DE FERTILIDADE DO SOLO - CFS RS/SC. Recomendações de adubação e calagem para os estados do Rio Grande do Sul e Santa Catarina. 3.ed. Passo Fundo: Sociedade Brasileira de Ciência do Solo - Núcleo Regional Sul; EMBRAPA/CNPT, 1995. 224p

EMBRAPA. Sistema brasileiro de classificação de solos. Centro Nacional de Pesquisa de Solos (Rio de Janeiro, RJ). Brasília: Embrapa - Serviço de Produção de Informação, 1999. $412 p$.

FONTANELI, R.S. et al. Sistemas de produção de grãos com pastagens anuais de inverno, sob plantio direto. Passo Fundo: Embrapa Trigo, 2000. 84p. (Circular Técnica, 6).

FLORES, J.P.C. Atributos de solo e rendimento de soja em um sistema de integração lavoura-pecuária com diferentes pressões de pastejo em plantio direto com aplicação de calcário na superfície. 2004. 74f. Dissertação (Mestrado em Ciência do Solo) - Programa de Pós-graduação em Ciência do Solo, Faculdade de Agronomia, Universidade Federal do Rio Grande do Sul.

GIACOMINI, S.J. et al. Matéria seca, relação C/N e acúmulo de nitrogênio, fósforo e potássio em misturas de plantas de cobertura de solo. Revista Brasileira de Ciência do Solo, Viçosa, v.27, p.325-334, 2003

IBGE. Censo Agropecuário 1995 - 1996. 1996. Capturado em 18 abr. 2004. Online. Disponível na Internet em: <http:/ /www.ibge.gov.br>.
LANZANOVA, M.E. Atributos físicos do solo em sistemas de culturas sob plantio direto na integração lavourapecuária. 2005. 132f. Dissertação (Mestrado em Ciência do Solo) - Programa de Pós-graduação em Ciência do Solo, Centro de Ciências Rurais, Universidade Federal de Santa Maria.

LOVATO, T. et al. Adição de carbono e nitrogênio e sua relação com os estoques no solo e o rendimento do milho em sistemas de manejo. Revista Brasileira de Ciência do Solo, Viçosa, v.28, p.175-187, 2004.

MIELNICZUK, J. Desenvolvimento de sistemas de culturas adaptadas à produtividade, conservação e recuperação de solos. In: CONGRESSO BRASILEIRO DE CIÊNCIA DO SOLO, 21. 1988, Campinas. A responsabilidade Social da Ciência do Solo. Anais... Campinas: SBCS, 1988. p.109-116.

MORAES, A. et al. Lavoura-pecuária em sistemas integrados na pequena propriedade. In: ENCONTRO LATINO AMERICANO SOBRE PLANTIO DIRETO NA PEQUENA PROPRIEDADE, 3., 1998, Pato Branco. Anais... Pato Branco: CEFET-PR, 1998. CD-ROM.

NICOLOSO, R.S. Dinâmica da matéria orgânica do solo em áreas de integração lavoura-pecuária sob sistema plantio direto. 2005. 149f. Dissertação (Mestrado em Ciência do Solo) - Programa de Pós-graduação em Ciência do Solo, Centro de Ciências Rurais, Universidade Federal de Santa Maria,

PADOVAN, M.R. et al. Avaliação de cultivares de soja, sob manejo orgânico, para fins de adubação verde e produção de grãos. Pesquisa Agropecuária Brasileira, Brasília, v.37, p.1705-1710, 2002.

RESTLE, J. et al. Eficiência e desempenho de categorias de bovinos de corte em pastagem cultivada. Revista Brasileira de Zootecnia, Viçosa, v.27, p.397-404, 1998.

ROVIRA, J. Manejo nutritivo de los rodeos de cría en pastoreo. Montevideo: Editorial Hemisferio Sur, 1996. 288p.

SÁ, J.C.M. et al. Avaliação do desenvolvimento radicular e atributos de genótipos de milho submetidos a níveis de palha no sistema plantio direto. Revista Plantio Direto, Passo Fundo, v.80, p.46-60, 2004.

TREIN, C.R. et al. Métodos de preparo do solo na cultura do milho e ressemeadura do trevo na rotação aveia+trevo/milho, após pastejo intensivo. Revista Brasileira de Ciência do Solo, Viçosa, v.15, p.105-111, 1991.

VOISIN, A. A produtividade do pasto. São Paulo: Mestre Jou, 1974. 520p. 